\title{
Kinetics and correlation analysis of reactivity in the oxidation of organic sulfides by butyltriphenylphosphonium dichromate
}

\author{
K M DILSHA and SEEMA KOTHARI ${ }^{1, *}$ \\ Department of Chemistry, J.N.V. University, Jodhpur 342005 \\ ${ }^{1} 4 \mathrm{~F} / 13$, New Power House Road, Jodhpur 342001 \\ e-mail: seema@goraexports.com
}

MS received 12 November 2008; revised 1 December 2008

\begin{abstract}
The oxidation of a number of monosubstituted aryl methyl, alkyl phenyl, dialkyl, and diphenyl sulfides by butyltriphenylphosphonium dichromate (BTPPD), to the corresponding sulfoxides, is first order with respect to BTPPD and is second order with respect to sulfide. The reaction is catalysed by hydrogen ions and the dependence is of second order. The oxidation of meta- and para-substituted aryl methyl sulfides correlated best in terms of Hammett equation, the reactions exhibited negative polar reaction constant. The ortho-substituted compounds correlated best in terms of Charton's triparametric equation with negative polar constant and a small degree of steric hindrance. The oxidation of alkyl phenyl sulfides exhibited a good correlation in terms of Pavelich-Taft equation confirming that the electron-donating power of the alkyl group increases the rate, however, the reactivity is not markedly controlled by the bulkiness of the alkyl group. The rates of oxidation of sulfides were determined in nineteen organic solvents. An analysis of the solvent effect by multi-parametric equations indicated the relatively greater importance of the cation-solvating power of the solvents. A mechanism involving a single-step electrophilic oxygen transfer from BTPPD to the sulfide leading to polar transition state has been proposed.
\end{abstract}

Keywords. Kinetics; mechanism; sulfides; oxidation; correlation analysis; $\mathrm{Cr}(\mathrm{VI})$ complex.

\section{Introduction}

Selective oxidation of organic compounds under nonaqueous conditions is an important transformation in synthetic organic chemistry. For this, a number of different chromium (VI) derivatives have been reported. ${ }^{1,2}$ Butyltriphenylphosphonium dichromate (BTPPD), a $\mathrm{Cr}(\mathrm{VI})$ derivative, reported to be a mild and selective oxidant. ${ }^{3}$ It oxidizes amines to azocompounds, thiols to disulphides and regenerates carbonyl compounds from their oximes. We have been interested in the kinetics and mechanism of the oxidation by BTPPD and a few reports have emanated from our laboratory. ${ }^{4-7}$ There seems to be no report on the mechanistic aspects of the oxidation of organic sulfides by BTPPD. In this paper, we report the kinetics of the oxidation of 34 organic sulfides by BTPPD in dimethyl sulphoxide (DMSO) as the solvent, with emphasis on structure-reactivity correlation. The mechanistic aspects are discussed.

\footnotetext{
*For correspondence
}

\section{Experimental}

\subsection{Materials}

The preparation, purification and specification of the sulfides have been described before. ${ }^{8}$ BTPPD was prepared by the reported method ${ }^{3}$ and its purity was checked by an iodometric method. The solvents were purified by the reported methods. ${ }^{9}$ (Amongst the solvents, $\mathrm{CS}_{2}$ is a flammable liquid and is toxic). Toluene $p$-sulphonic acid ( $\mathrm{Ts} \mathrm{OH})$ was used as a source of hydrogen ions.

\subsection{Product analysis}

Methyl phenyl sulfide $(0.01 \mathrm{~mol})$ and BTPPD $(0.01 \mathrm{~mol})$ were dissolved in DMSO $(50 \mathrm{ml})$ and the mixture was allowed to stand for approximately $20 \mathrm{~h}$ in the presence of $1.0 \mathrm{~mol} \mathrm{dm}^{-3} \mathrm{TsOH}$. Most of the solvent was removed under reduced pressure. The residue was diluted with water and extracted with chloroform $(3 \times 50 \mathrm{ml})$. The chloroform layer was dried over anhydrous $\mathrm{MgSO}_{4}$, the solvent was re- 
moved by evaporation and the residue was analysed by IR and ${ }^{1} \mathrm{H}$ NMR spectroscopy. The spectra were identical with those of MeSOPh. Peaks characteristic of $\mathrm{MeSPh}$ and $\mathrm{MeSO}_{2} \mathrm{Ph}$ could not be detected. Similar experiments were performed with other aryl methyl sulfides also. In all cases, the products were the corresponding sulfoxide only.

\subsection{Stoichiometry}

To determine the stoichiometry, BTPPD $(0.006 \mathrm{~mol})$ and different sulfides $(0.001 \mathrm{~mol})$ were made up to $100 \mathrm{ml}$ in DMSO in the presence of $1.0 \mathrm{~mol} \mathrm{dm}^{-3}$ $\mathrm{Ts} \mathrm{OH}$, in different experiments. The reaction was allowed to stand for $12 \mathrm{~h}$ to ensure the completion of the reaction. The residual BTPPD was determined spectrophotometrically. Several determinations with different concentrations of BTPPD and sulfide showed that the reaction exhibited $1: 3$ stoichiometry i.e. one mole of BTPPD was consumed with three moles of sulfide.

\subsection{Kinetic measurements}

Pseudo-first order conditions were attained by keeping a large excess $(\times 10$ or greater $)$ of the sulfides over the oxidant. The reactions were carried out at constant temperature $( \pm 0 \cdot 1 \mathrm{~K})$. Lower than the ambient temperature was obtained with the refrigerated bath circulator. The solvent was DMSO, unless stated otherwise. The reactions were followed by monitoring the decrease in the concentration of BTPPD at $364 \mathrm{~nm}$ for up to $80 \%$ of the reaction. The pseudo-first order rate constant, $k_{\mathrm{obs}}$, was evaluated from the linear $\left(r^{2}>0.995\right)$ plots of log [BTPPD] versus time. Duplicate kinetic runs showed that the rate constants were reproducible to within $\pm 3 \%$. The specific rate constant, $k$, was evaluated from the relation: $k=k_{\text {obs }} /$ [sulfide] $]^{2}\left[\mathrm{H}^{+}\right]^{2}$. In correlation analyses, we have used coefficient of determination $\left(C^{2}\right.$ or $\left.c^{2}\right)$, standard deviation (sd) and Exner's parameter, ${ }^{10} \psi$, as the measures of the goodness of fit.

\section{Results}

Rates and other experimental data were obtained for all the sulfides. Since the results are similar, only representative data are reproduced here.

Oxidation of organic sulfides by BTPPD resulted in the formation of the corresponding sulfides. The product analysis and the stoichiometry determination suggested the following overall reaction.

$$
\begin{gathered}
3 \mathrm{R}-\mathrm{S}-\mathrm{R}^{\prime}+\mathrm{Cr}_{2} \mathrm{O}_{7}^{-2}+8 \mathrm{H}^{+} \rightarrow 3 \mathrm{R}-\mathrm{S}-\mathrm{R}^{\prime}+2 \mathrm{Cr}^{+3}+4 \mathrm{H}_{2} \mathrm{O} . \\
\mathrm{O}
\end{gathered}
$$

\subsection{Rate laws}

The reactions were found to be of first order with respect to BTPPD. In individual kinetic runs, plots of $\log$ [BTPPD] versus time were linear $\left(c^{2}>0.995\right)$. Further, the pseudo-first order rate constants do not depend on the initial concentration of BTPPD (table 1). The reactions showed a second order dependence on the concentration of sulfide, as observed by the nearly constant values of $k_{\text {obs }} /\left[\right.$ sulfide] ${ }^{2}$ (table 1).

\subsection{Test for free radicals}

Oxidation of sulfides by BTPPD, in an atmosphere of nitrogen, failed to induce polymerization of acrylonitrile. In blank experiments, with the substrate absent, no noticeable consumption of BTPPD was observed. The addition of acrylonitrile had no effect on the rate of oxidation (table 1). To further confirm the absence of free radicals in the reaction pathway, the reaction was carried out in the presence of $0.05 \mathrm{~mol} \mathrm{dm}^{-3}$ of 2,6-di-t-butyl-4-methylphenol (butylated hydroxytoluene or BHT). It was observed that BHT was recovered unchanged, almost quantitatively.

\subsection{Effect of acidity}

Rates of oxidation of sulfides increase with an increase in acidity. The dependence on hydrogen ion concentration is of the form rate $=k\left[\mathrm{H}^{+}\right]^{2}$, as observed by the nearly constant values of $k_{\mathrm{obs}} /\left[\mathrm{H}^{+}\right]^{2}$ (table 2).

\subsection{Effect of temperature}

The rates of oxidation of 34 organic sulfides were determined at different temperatures and the activation parameters were calculated (table 3 ).

\subsection{Effect of solvent}

The oxidation of methyl phenyl sulfide by BTPPD was studied in nineteen organic solvents. The solubility of the reactants and the reaction of BTPPD with primary and secondary alcohols limited the choice of solvents. There was no reaction with the chosen 
Table 1. Rate constants for the oxidation of methyl phenyl sulfide by BTPPD at $288 \mathrm{~K}$.

\begin{tabular}{lcccc}
\hline $\begin{array}{l}{[\mathrm{MeSPh}]} \\
\left(\mathrm{mol} \mathrm{dm}^{-3}\right)\end{array}$ & $\begin{array}{c}10^{3}[\mathrm{BTPPD}] \\
\left(\mathrm{mol} \mathrm{dm}^{-3}\right)\end{array}$ & {$\left[\mathrm{H}^{+}\right]\left(\mathrm{mol} \mathrm{dm}^{-3}\right)$} & $10^{4} k_{\text {obs }}\left(\mathrm{s}^{-1}\right)$ & $10^{2} k_{\text {obs }} /[\mathrm{sulfide}]^{2}$ \\
\hline $0 \cdot 01$ & $1 \cdot 0$ & $1 \cdot 0$ & $0 \cdot 70$ & $70 \cdot 0$ \\
$0 \cdot 02$ & $1 \cdot 0$ & $1 \cdot 0$ & $2 \cdot 74$ & $68 \cdot 5$ \\
$0 \cdot 03$ & $1 \cdot 0$ & $1 \cdot 0$ & $6 \cdot 48$ & $72 \cdot 0$ \\
$0 \cdot 05$ & $1 \cdot 0$ & $1 \cdot 0$ & $18 \cdot 8$ & $75 \cdot 2$ \\
$0 \cdot 10$ & $1 \cdot 0$ & $1 \cdot 0$ & $71 \cdot 3$ & $71 \cdot 3$ \\
$0 \cdot 15$ & $1 \cdot 0$ & $1 \cdot 0$ & 158 & $70 \cdot 2$ \\
$0 \cdot 20$ & $1 \cdot 0$ & $1 \cdot 0$ & 280 & $70 \cdot 0$ \\
$0 \cdot 10$ & $0 \cdot 8$ & $1 \cdot 0$ & $72 \cdot 4$ & \\
$0 \cdot 10$ & $1 \cdot 5$ & $1 \cdot 0$ & $71 \cdot 0$ & \\
$0 \cdot 10$ & $2 \cdot 0$ & $1 \cdot 0$ & $71 \cdot 6$ & \\
$0 \cdot 10$ & $3 \cdot 0$ & $1 \cdot 0$ & $71 \cdot 5$ & \\
$0 \cdot 10$ & $5 \cdot 0$ & $1 \cdot 0$ & $72 \cdot 0$ & \\
$0 \cdot 05$ & $1 \cdot 0$ & $1 \cdot 0$ & $19 \cdot 0 *$ & \\
$0 \cdot 05$ & $1 \cdot 0$ & $1 \cdot 0$ & $18 \cdot 7 * *$ & \\
\hline
\end{tabular}

*Contains $0.005 \mathrm{~mol} \mathrm{dm}^{-3}$ acrylonitrile. **Contains $0.01 \mathrm{~mol} \mathrm{dm}^{-3}$ acrylonitrile

Table 2. Effect of acidity on the oxidation of phenyl methyl sulfide by BTPPD ${ }^{\mathrm{a}}$.

\begin{tabular}{lcccccr}
\hline$\left[\mathrm{H}^{+}\right] / \mathrm{mol} \mathrm{dm}^{-3}$ & 0.1 & 0.2 & 0.4 & 0.8 & 1.0 & 2.0 \\
$10^{4} k_{\text {obs }} / \mathrm{s}^{-1}$ & 0.19 & 0.72 & 3.19 & 11.9 & $18 \cdot 8$ & 71.7 \\
$10^{4} k_{\text {obs }} /\left[\mathrm{H}^{+}\right]^{2}$ & 19.0 & 18.0 & 19.9 & 18.6 & $18 \cdot 8$ & 17.9 \\
\hline${ }^{a}[\mathrm{MeSPh}]=0.05 \mathrm{~mol} \mathrm{dm}^{-3},[\mathrm{BTPPD}]=0.001 \mathrm{~mol} \mathrm{dm}^{-3}$, and temperature $=288 \mathrm{~K}$
\end{tabular}

solvents. The kinetics were similar in all the solvents. The values of the rate constant, $k$, are recorded in table 4 .

\section{Discussion}

The entropies and enthalpies of the activation of the oxidation of thirty-four organic sulfides were not satisfactorily correlated $\left(c^{2}=0.9102\right)$. According to Exner, ${ }^{11}$ an isokinetic relationship between the calculated values of the activation entropies and enthalpies is often vitiated by random experimental errors. Exner suggested an alternative method for establishing the isokinetic relationship. The correlation was tested and found genuine by applying Exner's criterion. ${ }^{11}$ The Exner's plot between the values of $\log k$ at $278 \mathrm{~K}$ and at $308 \mathrm{~K}$, for the thirty-four sulfides, is linear (slope $=0.8068 \pm 0.0204 ; c^{2}=0.9832$ ). The value of isokinetic temperature, determined by Exner's method, is $567 \pm 57 \mathrm{~K}$. A linear isokinetic relationship is, however, a necessary condition for the validity of linear free energy relationships. ${ }^{12}$ It also implies that all the reactions, so correlated, follow a similar mechanism.

\subsection{Solvent effect}

The values of the rate constant, $k$, in eighteen solvents $\left(\mathrm{CS}_{2}\right.$ was not considered as the complete range of the solvent parameters are not available), was correlated in terms of linear solvation energy relationship (LSER) of Kamlet et al. ${ }^{12}$

$$
\log k=A+p \pi^{*}+a \alpha+b \beta .
$$

Here, $\pi^{*}$ represents the solvent polarity for solventsolute interaction of non-specific type, $\beta$ is a scale of solvent hydrogen-bond acceptor basicity, while $\alpha$ represents the solvent hydrogen-bond donor acidity; $\mathrm{A}$ is the intercept term. It may be mentioned here that out of the 18 solvents, for 13 solvents $\alpha$ has a value of zero. The analyses in terms of (2), a twoparameter equation involving $\pi^{*}$ and $\beta$, and separately with $\pi^{*}$ and $\beta$ gave the following results. Here $n$ is the number of data points.

$$
\begin{aligned}
& \log k=-2.06+1.57 \pm 020 \pi^{*}-0 \cdot 17 \pm 0 \cdot 15 \alpha+ \\
& 0 \cdot 18 \pm 0 \cdot 16 \beta \\
& c^{2}=0.8572, \mathrm{sd}=0 \cdot 18, n=18, \psi=0.41
\end{aligned}
$$


Table 3. Rate constants and activation parameters for the oxidation of sulfides by BTPPD.

\begin{tabular}{|c|c|c|c|c|c|c|c|}
\hline \multirow[b]{2}{*}{ Subst. } & \multicolumn{4}{|c|}{$10^{2} \mathrm{k}\left(\mathrm{mol}^{-4} \mathrm{dm}^{12} \mathrm{~s}^{-1}\right)$ at temp. $(\mathrm{K})$} & \multirow[b]{2}{*}{$\Delta H^{*}\left(\mathrm{~kJ} \mathrm{~mol}^{-1}\right)$} & \multirow[b]{2}{*}{$\Delta S^{*}\left(\mathrm{~J} \mathrm{~mol}^{-1} \mathrm{~K}^{-1}\right)$} & \multirow[b]{2}{*}{$\Delta G^{*}\left(\mathrm{~kJ} \mathrm{~mol}{ }^{-1}\right)$} \\
\hline & $278 \mathrm{~K}$ & $288 \mathrm{~K}$ & $298 \mathrm{~K}$ & $308 \mathrm{~K}$ & & & \\
\hline \multicolumn{8}{|c|}{ (i) Aryl methyl sulfides } \\
\hline $\mathrm{H}$ & $36 \cdot 0$ & $71 \cdot 3$ & 139 & 267 & $45 \cdot 0 \pm 0 \cdot 5$ & $-92 \pm 2$ & $72 \cdot 2 \pm 0 \cdot 4$ \\
\hline $\mathrm{p}-\mathrm{Me}$ & $82 \cdot 2$ & 153 & 276 & 515 & $40 \cdot 8 \pm 0 \cdot 7$ & $-100 \pm 2$ & $70 \cdot 4 \pm 0 \cdot 5$ \\
\hline $\mathrm{p}-\mathrm{OMe}$ & 140 & 225 & 396 & 718 & $36 \cdot 3 \pm 1 \cdot 5$ & $-112 \pm 5$ & $69 \cdot 5 \pm 1 \cdot 2$ \\
\hline $\mathrm{p}-\mathrm{F}$ & $26 \cdot 3$ & $56 \cdot 0$ & 111 & 220 & $47.7 \pm 0.3$ & $-84 \pm 1$ & $72 \cdot 7 \pm 0 \cdot 2$ \\
\hline $\mathrm{p}-\mathrm{Cl}$ & $12 \cdot 0$ & $25 \cdot 4$ & $54 \cdot 1$ & 113 & $50 \cdot 7 \pm 0.7$ & $-80 \pm 2$ & $74 \cdot 5 \pm 0 \cdot 5$ \\
\hline $\mathrm{p}-\mathrm{Br}$ & $12 \cdot 1$ & $25 \cdot 2$ & $54 \cdot 2$ & 111 & $50 \cdot 2 \pm 0 \cdot 7$ & $-82 \pm 2$ & $74 \cdot 5 \pm 0 \cdot 6$ \\
\hline $\mathrm{p}-\mathrm{NO}_{2}$ & 0.78 & $2 \cdot 37$ & $6 \cdot 23$ & $15 \cdot 2$ & $67 \cdot 8 \pm 0 \cdot 7$ & $-41 \pm 2$ & $79.9 \pm 0.5$ \\
\hline $\mathrm{p}-\mathrm{COMe}$ & 2.79 & 6.98 & $17 \cdot 0$ & $38 \cdot 4$ & $59 \cdot 8 \pm 0 \cdot 2$ & $-60 \pm 1$ & $77 \cdot 4 \pm 0 \cdot 1$ \\
\hline $\mathrm{p}-\mathrm{CO}_{2} \mathrm{Me}$ & $7 \cdot 92$ & $18 \cdot 6$ & $41 \cdot 2$ & $86 \cdot 2$ & $54 \cdot 1 \pm 0 \cdot 3$ & $-71 \pm 1$ & $75 \cdot 2 \pm 0 \cdot 1$ \\
\hline $\mathrm{p}$-NHAc & 38.0 & $73 \cdot 0$ & 141 & 279 & $44.7 \pm 0.9$ & $-92 \pm 3$ & $72 \cdot 1 \pm 0.7$ \\
\hline $\mathrm{p}-\mathrm{NH}_{2}$ & 958 & 1295 & 1930 & 3138 & $25 \cdot 6 \pm 1 \cdot 8$ & $-135 \pm 6$ & $65 \cdot 6 \pm 1 \cdot 4$ \\
\hline $\mathrm{m}-\mathrm{Me}$ & $49 \cdot 9$ & $93 \cdot 4$ & 178 & 341 & $43 \cdot 1 \pm 0 \cdot 8$ & $-96 \pm 3$ & $71.5 \pm 0.7$ \\
\hline m-OMe & $21 \cdot 6$ & $44 \cdot 5$ & $91 \cdot 3$ & 182 & $48 \cdot 1 \pm 0 \cdot 5$ & $-85 \pm 2$ & $73 \cdot 2 \pm 0 \cdot 4$ \\
\hline $\mathrm{m}-\mathrm{Cl}$ & $5 \cdot 71$ & $13 \cdot 6$ & $30 \cdot 9$ & $66 \cdot 7$ & $55 \cdot 8 \pm 0 \cdot 1$ & $-68 \pm 1$ & $75 \cdot 9 \pm 0 \cdot 1$ \\
\hline $\mathrm{m}-\mathrm{Br}$ & $5 \cdot 42$ & $13 \cdot 1$ & $29 \cdot 7$ & $64 \cdot 8$ & $56 \cdot 3 \pm 0 \cdot 1$ & $-67 \pm 1$ & $76 \cdot 0 \pm 0 \cdot 1$ \\
\hline m-I & 8.95 & $20 \cdot 4$ & $44 \cdot 1$ & $97 \cdot 5$ & $53 \cdot 9 \pm 0 \cdot 6$ & $-71 \pm 2$ & $75 \cdot 0 \pm 0 \cdot 5$ \\
\hline $\mathrm{m}-\mathrm{NO}_{2}$ & $1 \cdot 10$ & $3 \cdot 20$ & $8 \cdot 32$ & $19 \cdot 0$ & $65 \cdot 2 \pm 0 \cdot 8$ & $-48 \pm 3$ & $79 \cdot 3 \pm 0 \cdot 7$ \\
\hline $\mathrm{m}-\mathrm{CO}_{2} \mathrm{Me}$ & $6 \cdot 38$ & $14 \cdot 9$ & $35 \cdot 0$ & $75 \cdot 0$ & $56 \cdot 2 \pm 0 \cdot 4$ & $-66 \pm 1$ & $75 \cdot 6 \pm 0 \cdot 3$ \\
\hline $\mathrm{o}-\mathrm{Me}$ & $20 \cdot 6$ & $43 \cdot 0$ & $88 \cdot 3$ & 180 & $48 \cdot 9 \pm 0 \cdot 6$ & $-82 \pm 2$ & $73 \cdot 3 \pm 0 \cdot 5$ \\
\hline o-OMe & $13 \cdot 6$ & $27 \cdot 1$ & $53 \cdot 1$ & 105 & $45 \cdot 9 \pm 0 \cdot 6$ & $-97 \pm 2$ & $74 \cdot 5 \pm 0 \cdot 5$ \\
\hline $\mathrm{o}-\mathrm{NO}_{2}$ & $1 \cdot 30$ & $3 \cdot 31$ & $7 \cdot 69$ & $16 \cdot 8$ & $58 \cdot 2 \pm 0 \cdot 3$ & $-72 \pm 1$ & $79 \cdot 4 \pm 0 \cdot 2$ \\
\hline $\mathrm{o}-\mathrm{CO}_{2} \mathrm{Me}$ & 138 & 333 & 735 & 1565 & $55 \cdot 0 \pm 0 \cdot 2$ & $-44 \pm 1$ & $68 \cdot 1 \pm 0 \cdot 1$ \\
\hline $\mathrm{o}-\mathrm{NH}_{2}$ & 31.7 & $60 \cdot 1$ & 110 & 213 & $42 \cdot 4 \pm 0.9$ & $-102 \pm 3$ & $72.7 \pm 0.7$ \\
\hline $0-\mathrm{Cl}$ & $3 \cdot 25$ & $7 \cdot 47$ & $16 \cdot 2$ & $35 \cdot 1$ & $53 \cdot 8 \pm 0.4$ & $-80 \pm 1$ & $77 \cdot 5 \pm 0 \cdot 3$ \\
\hline $0-\mathrm{Br}$ & $2 \cdot 85$ & $6 \cdot 81$ & $15 \cdot 3$ & $32 \cdot 5$ & $56 \cdot 8 \pm 0 \cdot 6$ & $-70 \pm 2$ & $77 \cdot 6 \pm 0.5$ \\
\hline o-I & $2 \cdot 62$ & $6 \cdot 21$ & $14 \cdot 2$ & $32 \cdot 1$ & $57 \cdot 1 \pm 0 \cdot 6$ & $-70 \pm 2$ & $77 \cdot 8 \pm 0 \cdot 5$ \\
\hline o-CN & $1 \cdot 82$ & $4 \cdot 61$ & $10 \cdot 6$ & $21 \cdot 9$ & $56 \cdot 6 \pm 0 \cdot 7$ & $-75 \pm 2$ & $78 \cdot 6 \pm 0 \cdot 6$ \\
\hline \multicolumn{8}{|c|}{ (ii) Alkyl phenyl sulfides } \\
\hline $\mathrm{Et}$ & $52 \cdot 4$ & 102 & 195 & 373 & $44 \cdot 0 \pm 0 \cdot 5$ & $-92 \pm 2$ & $71 \cdot 3 \pm 0 \cdot 4$ \\
\hline $\operatorname{Pr}$ & $39 \cdot 2$ & $78 \cdot 9$ & 156 & 304 & $46 \cdot 1 \pm 0 \cdot 4$ & $-87 \pm 2$ & $71 \cdot 9 \pm 0 \cdot 4$ \\
\hline i-Pr & $48 \cdot 6$ & $97 \cdot 3$ & 194 & 375 & $46 \cdot 0 \pm 0 \cdot 4$ & $-86 \pm 1$ & $71 \cdot 4 \pm 0 \cdot 3$ \\
\hline $\mathrm{t}-\mathrm{Bu}$ & $21 \cdot 3$ & $49 \cdot 9$ & 108 & 226 & $53 \cdot 4 \pm 0 \cdot 1$ & $-66 \pm 1$ & $72 \cdot 8 \pm 0 \cdot 1$ \\
\hline \multicolumn{8}{|c|}{ (iii) other sulfides } \\
\hline $\mathrm{Me}_{2} \mathrm{~S}$ & $74 \cdot 3$ & 145 & 288 & 550 & $45 \cdot 1 \pm 0 \cdot 6$ & $-85 \pm 2$ & $70 \cdot 4 \pm 0 \cdot 5$ \\
\hline $\mathrm{Pr}_{2} \mathrm{~S}$ & 140 & 295 & 530 & 851 & $40 \cdot 3 \pm 1 \cdot 4$ & $-97 \pm 5$ & $69 \cdot 0 \pm 1 \cdot 2$ \\
\hline $\mathrm{Ph}_{2} \mathrm{~S}$ & $5 \cdot 05$ & $9 \cdot 75$ & $22 \cdot 8$ & $42 \cdot 1$ & $48 \cdot 8 \pm 1 \cdot 5$ & $-95 \pm 5$ & $76 \cdot 8 \pm 1 \cdot 2$ \\
\hline
\end{tabular}

$$
\begin{aligned}
& \log k=-2 \cdot 00+1 \cdot 63 \pm 0 \cdot 19 \pi^{*}+0 \cdot 12 \pm 0 \cdot 16 \beta \\
& c^{2}=0 \cdot 8441, \mathrm{sd}=0 \cdot 18, n=18, \psi=0.42 \\
& \log k=-2.03+1 \cdot 66 \pm 0 \cdot 18 \pi^{*} \\
& c^{2}=0 \cdot 8285, \mathrm{sd}=0 \cdot 19, n=18, \psi=0.41 \\
& \log k=-2.96+0.41 \pm 0.36 \beta \\
& c^{2}=0.0776, \mathrm{sd}=0.43, n=18, \psi=0.99
\end{aligned}
$$

The results show that $c a$. $86 \%$ of the data on the solvent effect is explained by (2). According to Exner's criterion, ${ }^{10}$ however, the correlation is poor. The major contribution is from the solvent polarity term, $\pi^{*}$. Both $\alpha$ and $\beta$ play relatively insignificant roles. There is no significant collinearity between $\pi^{*}$ and $\beta$ for the eighteen solvents $\left(c^{2}=0.0477\right.$, $\mathrm{sd}=0.24)$.

The data on solvent effect were analysed in terms of Swain's equation ${ }^{13}$ also, where A represents the anion-solvating power of the solvent and $\mathrm{B}$ the cation-solvating power; $\mathrm{C}$ is the intercept term, and $(\mathrm{A}+\mathrm{B})$ is postulated to represent the solvent polarity.

$$
\log k=a A+b B+C \text {. }
$$


Table 4. Rate constants for the oxidation of methyl phenyl sulfide by BTPPD in different solvents at $288 \mathrm{~K}$.

\begin{tabular}{|c|c|c|c|}
\hline Solvent & $10^{2} \mathrm{k}\left(\mathrm{mol}^{-4} \mathrm{dm}^{12} \mathrm{~s}^{-1}\right)$ & Solvent & 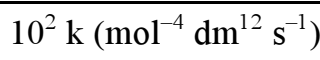 \\
\hline Chloroform & $20 \cdot 2$ & Tetrahydrofurane & $11 \cdot 6$ \\
\hline 1,2-Dichloroethane & $25 \cdot 0$ & tert-butylalcohol & $8 \cdot 35$ \\
\hline Dichloromethane & $22 \cdot 7$ & Dioxane & $11 \cdot 9$ \\
\hline DMSO & $71 \cdot 3$ & 1,2-Dimethoxyethane & $6 \cdot 15$ \\
\hline Acetone & $22 \cdot 2$ & Acetic acid & 3.68 \\
\hline DMF & $36 \cdot 8$ & Ethyl acetate & $8 \cdot 72$ \\
\hline Butanone & $16 \cdot 5$ & Carbon disulfide & $3 \cdot 35$ \\
\hline Nitrobenzene & $27 \cdot 6$ & & \\
\hline Benzene & $8 \cdot 22$ & & \\
\hline Cyclohexane & $0 \cdot 87$ & & \\
\hline Toluene & $6 \cdot 65$ & & \\
\hline Acetophenone & 29.9 & & \\
\hline
\end{tabular}

The results of the correlation analyses in terms of (7), individually with $\mathrm{A}$ and $\mathrm{B}$, and with $(\mathrm{A}+\mathrm{B})$ are given below.

$$
\begin{aligned}
& \log k=0.55 \pm 0 \cdot 01 A+1 \cdot 70 \pm 0 \cdot 01 B-2 \cdot 17 \\
& c^{2}=0.9998, \mathrm{sd}=0 \cdot 01, n=19, \psi=0.02 \\
& \log k=0 \cdot 31 \pm 0.56 A-2.99 \\
& c^{2}=0.0181, \mathrm{sd}=0.45, n=19, \psi=1.0 \\
& \log k=1.65 \pm 0 \cdot 10 B-2.01 \\
& c^{2}=0.9436, \mathrm{sd}=0 \cdot 11, n=19, \psi=0.24 \\
& \log k=1 \cdot 32 \pm 0 \cdot 15(A+B)-2 \cdot 14 \\
& c^{2}=0.8273, \mathrm{sd}=0 \cdot 19, n=19, \psi=0.43 .
\end{aligned}
$$

The data on solvent effect showed an excellent correlation in terms of Swain's equation ${ }^{13}$ with both anion- and cation-solvating powers contributing to the observed solvent effect. However, the role of cationsolvation is major, it alone accounts for ca. $94 \%$ of the data. There is no significant collinearity between $A$ and $B$ for the nineteen solvents $\left(c^{2}=0.0108 ; \mathrm{sd}=\right.$ $0 \cdot 27)$. The solvent polarity, represented by $(A+B)$ accounted for $c a .83 \%$ of the data. In view of the fact that $c a .83 \%$ of the data is accounted for by $(A+B)$, an attempt was made to correlate the data with the relative permittivity of the solvents. A plot of $\log k$ against the inverse of the relative permittivity, however, is not linear $\left(c^{2}=0.5078\right)$.

The solvent polarity term of Kamlet's equation ${ }^{12}$ explained $c a .83 \%$ of the data. Thus it seems that the solvent polarity terms of the two equations represent nearly the same solvent property. This is borne out by the fact that there is a significant collinearity between $\pi^{*}$ and $(A+B)$ for the eighteen solvents $\left(c^{2}=0.7811\right)$.
Table 5. Correlation of the rates of the oxidation of meta- and para-substituted aryl methyl sulfides in Hammett equation ${ }^{\mathrm{a}}$.

\begin{tabular}{lcccc}
\hline Temp./K & $\rho$ & $R^{2}$ & $\mathrm{sd}$ & $\Psi$ \\
\hline 278 & $-2.12 \pm 0.03$ & 0.9975 & 0.039 & 0.051 \\
288 & $-1.89 \pm 0.02$ & 0.9974 & 0.035 & 0.052 \\
298 & $-1.71 \pm 0.02$ & 0.9972 & 0.033 & 0.054 \\
308 & $-1.59 \pm 0.02$ & 0.9964 & 0.035 & 0.062 \\
\hline
\end{tabular}

${ }^{\mathrm{a}}$ No. of data points $=18$

The solvent effect suggests that the transition state is more polar than the reactants. This indicates an attack of electrofilic BTPPD-oxygen on electronrich sulfur resulting in the formation of positive polarisation of sulfur atom and negative polarisation of oxygen atom. The increased polarity of the transition state implies the increase in rate with an increase in the polarity of the solvent. This is justified by observed rate data.

\subsection{Correlation analysis of reactivity}

The rates of oxidation of meta-and para-substituted aryl methyl sulfides correlate well with Hammett ${ }^{14}$ substituent constant yielding negative reaction constant (table 5). The negative reaction constant points to a generation of electron-deficient centre in the transition state indicating an electrophilic attack of BTPPD on sulfur atom. The magnitude of reaction constant is smaller than those observed in the oxidation reactions proceeding via the formation of halogenosulfonium cation in the rate-determining step. The values of $\rho$ for the formation of $\mathrm{RArSCl}^{+}$and RArSBr ${ }^{+}$were -4.25 and -3.20 respectively. ${ }^{15,16}$ This indicates that in the transition state of the present 
Table 6. Correlation of rate of oxidation of alkyl phenyl sulfides by BTPPD in terms of Pavelich-Taft equation ${ }^{\mathrm{a}}$.

\begin{tabular}{lccccc}
\hline Temp./K & $\rho^{*}$ & $\delta$ & $R^{2}$ & sd & $\Psi$ \\
\hline 278 & $-2.02 \pm 0.01$ & $-0.54 \pm 0.01$ & 0.9999 & 0.001 & 0.013 \\
288 & $-1.86 \pm 0.03$ & $-0.46 \pm 0.01$ & 0.9998 & 0.003 & 0.018 \\
298 & $-1.78 \pm 0.04$ & $-0.42 \pm 0.01$ & 0.9995 & 0.005 & 0.029 \\
308 & $-1.72 \pm 0.03$ & $-0.38 \pm 0.01$ & 0.9996 & 0.002 & 0.026 \\
\hline
\end{tabular}

${ }^{\mathrm{a}}$ No. of data points $=5$

reaction, the electron-deficiency on the sulfur atom is not very high, but similar to that observed in the oxidation of sulfides by periodate $\operatorname{ion}^{17}(\rho=1.40)$, permanganate $^{18}(-1.52)$ and pyridinium fluorochromate $^{19}(-1.65)$, where the oxidation of sulfides is involving a direct oxygen transfer via an electriphillic attack on the sulfide-sulfur.

The rates of oxidation of alkyl phenyl sulfides did not yield any significant correlation separately with Taft's $\sigma^{*}$ or $E_{\mathrm{s}}$ values. ${ }^{14}$ The rates were, therefore, analysed in terms of Pavelich-Taft's ${ }^{20}$ dual-substituent parameter (DSP) (12).

$$
\log k=\rho^{*} \sigma^{*}+\delta E_{\mathrm{s}}+\log k_{0} .
$$

The correlations are excellent (table 6). Though the number of compounds is small (five) for an analysis by a DSP equation, the results can be used qualitatively. The negative polar reaction constant confirms the generation of electron-deficient centre in the rate-determining step, resulting in an enhancement of the reaction rate with an increase in the electron-donating power of the alkyl group. The steric effect plays a minor inhibitory role.

The rates of oxidation of ortho-substituted aryl methyl sulfides did not yield a significant correlation with either Taft's polar or steric substituent constants. ${ }^{21}$ The rates were, therefore, analysed in terms of Charton's (13) and (14). ${ }^{22}$ Here, $\sigma_{\mathrm{I}}, \sigma_{\mathrm{R}}$ and $V$ represents field, resonance and steric substituent constants, respectively. The values used were those compiled by Aslem et al $^{23}$

$$
\begin{aligned}
& \log k=\alpha \sigma_{\mathrm{I}}+\beta \sigma_{\mathrm{R}}+h, \\
& \log k=\alpha \sigma_{\mathrm{I}}+\beta \sigma_{\mathrm{R}}+\varphi \mathrm{V}+h .
\end{aligned}
$$

In multiple linear regression, using (13), the coefficient of multiple correlation is poor and the sd is high (15). The coffecient of correlation is also poor in terms of (14), if all the ortho compounds are included (16). However, the correlation improves substantially if the rate data of o-COOMe is not included (17)

$$
\begin{aligned}
& \log k=-1.98 \pm 0.77 \sigma_{\mathrm{I}}+0.28 \pm 0.59 \sigma_{\mathrm{R}}+0.66 \\
& \begin{array}{c}
c^{2}=0.4916, \mathrm{sd}=0.50, n=10, \psi=0.79, T=308 \mathrm{~K} \\
\log k=-1.96 \pm 0.91 \sigma_{\mathrm{I}}+0.27 \pm 0.64 \sigma_{\mathrm{R}}-0.06 \pm \\
\quad 0.94 \mathrm{~V}+0.67
\end{array} \\
& \begin{array}{c}
c^{2}=0.4920, \mathrm{sd}=0.54, n=10, \psi=0.85, T=308 \mathrm{~K} \\
\log k=-1.50 \pm 0.02 \sigma_{\mathrm{I}}-0.39 \pm 0.01 \sigma_{\mathrm{R}}- \\
\quad 0.49 \pm 0.02 \mathrm{~V}-0.43
\end{array} \\
& c^{2}=0.9996, \mathrm{sd}=0.01, n=9, \psi=0.03
\end{aligned}
$$

The behaviour of o- $\mathrm{NO}_{2}$ is consistent with the planar confirmation.

The deviations noted in the case of o-COOMe substituted compound can be attributed to the moderate anchimeric assistance provided by this group to the reaction by stabilising the positively polarised sulfur in the transition state. The values of $k$ for the oxidation of o-COOMe substituted sulfides, calculated by (14), is $44.4 \times 10^{-2} \mathrm{~mol}^{-4} \mathrm{dm}^{12} \mathrm{~s}^{-1}$, whereas the observed value is $1565 \times 10^{-2} \mathrm{~mol}^{-4} \mathrm{dm}^{12} \mathrm{~s}^{-1}$. The rate-enhancement observed may be caused due to neighbouring group participation.

The reaction constants and other statistical data for the ortho-substituted aryl methyl sulfides are reported in table 7 . The contribution of the resonance effect to the polar effects, $P_{\mathrm{R}}$, and that of steric effect to the total effect of the ortho group, $P_{\mathrm{S}}$, were calculated by Charton's method. ${ }^{22}$ The results showed that, in the oxidation of ortho-compounds also the field effect is predominating as in the case of meta- and para-substituted aryl methyl sulfides,. The resonance and steric effects play relatively a minor role.

\subsection{Mechanism}

A one-electron oxidation, giving rise to free radicals, is unlikely in view of the failure to induce polymerisation of acrylonitrile. BHT is an excellent trap for free radicals. ${ }^{24}$ The fact that BHT was 
Table 7. Correlation of the rates of the oxidation of ortho-substituted aryl methyl sulfides by Charton's method.

\begin{tabular}{ccccccccc}
\hline $\mathrm{T} / \mathrm{K}$ & $\alpha$ & $\beta$ & $\phi$ & $R^{2}$ & sd & $P_{\mathrm{s}}$ & $P_{\mathrm{R}}$ & $\Psi$ \\
\hline 278 & $-1.71 \pm 0.01$ & $-0.59 \pm 0.01$ & $-0.70 \pm 0.01$ & 0.9998 & 0.008 & $23 \cdot 3$ & 25.7 & 0.012 \\
288 & $-1.60 \pm 0.02$ & $-0.50 \pm 0.02$ & $-0.64 \pm 0.02$ & 0.9995 & 0.014 & 23.4 & $24 \cdot 3$ & 0.027 \\
298 & $-1.53 \pm 0.02$ & $-0.42 \pm 0.02$ & $-0.56 \pm 0.02$ & 0.9994 & 0.015 & 22.5 & 21.9 & 0.030 \\
308 & $-1.50 \pm 0.02$ & $-0.39 \pm 0.01$ & $-0.49 \pm 0.02$ & 0.9996 & 0.012 & 20.9 & 21.2 & 0.027 \\
\hline
\end{tabular}

$$
\begin{gathered}
\left(\mathrm{R}_{1} \mathrm{P}_{2} \mathrm{Cr}_{2} \mathrm{O}_{7} \Leftrightarrow 2 \mathrm{R}_{1} \mathrm{P}^{+}+\mathrm{Cr}_{2} \mathrm{O}_{7}^{-2}\right. \\
\mathrm{Cr}_{2} \mathrm{O}_{7}^{-2}+2 \mathrm{H}^{+} \Leftrightarrow \mathrm{H}_{2} \mathrm{Cr}_{2} \mathrm{O}_{7} \\
2 \mathrm{R}-\mathrm{S}-\mathrm{R}^{\prime}+\mathrm{H}_{2} \mathrm{Cr}_{2} \mathrm{O}_{7} \\
\text { slow }
\end{gathered}
$$

Scheme 1.

recovered unchanged also goes against the occurrence of a one-electron oxidation.

The analysis of the solvent effect indicated the importance of the cation-solvating power of the solvent. The observed results can be explained on the basis of two alternative mechanisms. BTPPD may be ionised in DMSO to butyltriphenylphosphonium and dichromate ions. The formation of a cation is supported by the major role of the cation-solvating power of the solvent. The dichromate ion undergoes diprotonation followed by a rate-determining electrophilic attack of BTPPD-oxygen to electron-rich sulfur to produce the corresponding sulfoxide via an $S_{N} 2$ type transition state (scheme 1). A low magni- tude of polar reaction constant and the moderate degree of anchimeric assistance by the neighbouring groups also support a transition state depicted in the scheme 1, rather than the formation of sulphonium ion. The $S_{N} 2$ type transition state is also supported by the solvent effect. Alternatively, BTPPD may get diprotonated first which then undergoes a ratedetermining nucleophilic attack of a electron-rich sulfur atom on BTPPD oxygen atom resulting in a oxygen atom transfer to sulfide molecule to give the corresponding sulfoxide (scheme 2). The similar type of mechanism involving oxygen atom transfer in the rate-determining step is also suggested in the oxidation of sulfides by pyridinium fluorochromate $(\mathrm{PFC})^{19}$ and hydrogen peroxide. ${ }^{25}$ The rate-determining step may be viewed as an $S_{N} 2$ process. The solvent effect supports the protonation step as well as a $S_{N} 2$ like transition state. The value of entropy of activation in this reaction is close to the values observed in the reactions involving oxygen atom transfer. ${ }^{19,25}$ This supports the proposed mechanism. It may be mentioned here that though the step of the diprotonation is shown as a single-step, it must be taking place in two steps.

Initially $\mathrm{Cr}(\mathrm{VI})$ is reduced to $\mathrm{Cr}(\mathrm{IV})$. It is likely to react with another $\mathrm{Cr}(\mathrm{VI})$ to generate $\mathrm{Cr}(\mathrm{V})$ which is then reduced in a fast step to the ultimate product $\mathrm{Cr}$ (III). Such a sequence of reactions in $\mathrm{Cr}(\mathrm{VI})$ oxidations is well known. ${ }^{26}$

The oxidation of sulfides by BTPPD may involve a cyclic intermediate as well, as has been suggested in many reactions of $\mathrm{Cr}(\mathrm{VI}){ }^{27}$ However, a cyclic intermediate may also exhibit a sulfurane structure. The cyclic intermediate would be highly strained in view of the apical position of a lone pair of electrons or an alkyl group. The steric requirements of the reaction, involving a cyclic intermediate, would be higher as compared to those of reactions involving $S_{N} 2$ type intermediate and the observed small values of steric reaction constant are thus consistent with the proposed acyclic sulfurane mechanism. The formation of cyclic sulfurane intermediate also entails a more exacting specificity orientation and should result in a much larger entropy of activation than 
observed. The values of the entropy of activation obtained in this reaction is close to the values observed in typical reactions involving oxygen transfer e.g. oxidation of MeSPh by periodate, ${ }^{17} \mathrm{PFC},{ }^{19}$ and by hydrogen peroxide ${ }^{25}\left(\Delta S^{*}=-89,-113\right.$ and $-115 \mathrm{~J} \mathrm{~mol}^{-1} \mathrm{~K}^{-1}$ respectively).

It is of interest here to compare the kinetics of the oxidation of organic sulfides by other $\mathrm{Cr}(\mathrm{VI}) \mathrm{com}$ plexes. It is observed that the oxidation of sulfides by PFC, ${ }^{19}$ pyridinium bromochromate, ${ }^{28}$ and $2,2^{\prime}$ bipyridinium chlorochromate ${ }^{29}$ reported a similar kinetics i.e. the reactions are of first order with respect to each of the oxidant and the reductant. However, the oxidation by pyridinium chlorochromate ${ }^{30}$ exhibited Michaelis-Menten type kinetics. A mechanism involving a rate-determining electrophilic oxygen transfer from the oxidant to the sulfide has been proposed in all the oxidation reactions. The kinetics of the oxidation of diethyl sulfide by pyridinium dichromate (PDC), ${ }^{31}$ in acetonitrile, exhibited first order kinetics with respect to each PDC and sulfide and of second order dependence on $\mathrm{TsOH}$. In case of

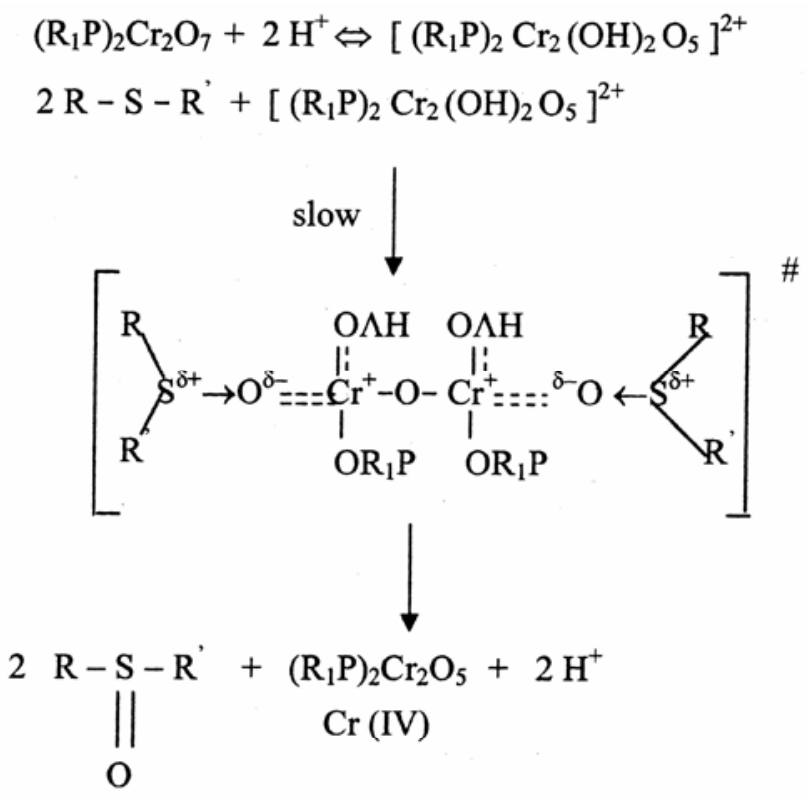

$$
\begin{gathered}
\mathrm{Cr}(\mathrm{IV})+\mathrm{Cr}(\mathrm{VI}) \stackrel{\text { fast }}{\rightarrow} \mathrm{Cr}(\mathrm{V}) \\
\mathrm{Cr}(\mathrm{V})+\mathrm{R}-\mathrm{S}^{\prime}-\mathrm{R}^{\prime} \rightarrow \text { Product }+\mathrm{Cr}(\mathrm{III})+2 \mathrm{H}^{+} \\
\mathrm{R}_{1}=\text { butyltriphenyl }
\end{gathered}
$$

Scheme 2. aryl methyl sulfides, the order with respect to TsOH is $>1$ and $<2$, while Michaelis-Menten type kinetics were observed with respect to the sulfide. A nonlinear Hammett plot was obtained with both electron-donating and electron-withdrawing groups slowing down the rate of reaction. The reaction was retarded by acrylonitrile, thereby indicating a oneelectron oxidation giving rise to free radicals. Thus, it is observed that the mode of oxidation depends on the nature of the oxidant.

The observed negative entropy of activation supports the proposed mechanism. As the charge separation takes place, in the transition state of the ratedetermining step, the charged ends become highly solvated. This results in an immobilisation of a large number of solvent molecules, reflected in the loss of entropy.

\section{Acknowledgement}

Thanks are due to the University Grants Commission (India) for the financial support.

\section{References}

1. Corey E J and Suggs W J 1975 Tetrahedron Lett. 2647; Bhattacharya M M, Chaudhuri M K, Dasgupta H S, Roy N and Kathing D T 1982 Synthesis 588

2. Li M and Johnson M E 1995 Synth. Commun. 25 533; Firouzabadi H and Sharifi A 1992 Synthesis 999

3. Baltork I M, Sadeghi M M, Mahmoodi N and Kharmesh B 1997 Indian J. Chem. B36 438

4. Kothari A, Kothari S and Banerji K K 2000 Oxidn. Commun. 2393

5. Kothari A, Kothari S and Banerji K K 2000 Indian J. Chem. A39 734

6. Goyal A, Kothari S and Banerji K K $2002 \mathrm{~J}$. Chem. Res.(S) 363; (M) 0863

7. Dilsha K M and Kothari S 2007 Prog. Reac. Kinet. Mech. 32119.

8. Goel S, Varshney S, Kothari S and Banerji K K 1996 J.Chem.Res. (S) 510; (M) 2901

9. Perrin D D, Armarego W L, Perrin D R 1980 Purification of laboratory chemicals (New York: Pergamon)

10. Exner O 1966 Collect. Czech. Chem. Commun. 31 3222

11. Exner O 1964 Collect. Czech. Chem. Commun. 29 1094

12. Kamlet M J, Abboud J L M and Abraham M H and Taft R W 1983 J. Org. Chem. 482877 and references cited therein

13. Swain C G, Swain M S, Powell A L and Alumni S 1983 J. Am. Chem. Soc. 105502

14. Wiberg K B 1963 Physical organic chemistry (New York: John Wiley) 
15. Ruff F and Kucsman A 1975 J. Chem. Soc. Perkin Trans. 2. 509; Ruff F and Kucsman A 1982 J. Chem. Soc. Perkin Trans. 2. 1075

16. Ruff F, Komoto K, Furoukawa N and Oae S 1976 Tetrahedron 322763

17. Ruff F and Kucsman A 1985 J. Chem. Soc. Perkin Trans. 2. 683

18. Banerji K K 1988 Tetrahedron 442969

19. Banerji K K 1988 J. Chem. Soc. Perkin Trans. 22065

20. Pavelich W H and Taft R W $1957 \mathrm{~J}$. Am. Chem. Soc. 794935

21. Jones R 1991 Physical mechanistic organic chemistry (Cambridge: Cambridge University Press)

22. Charton M 1971 Prog. Phys. Org. Chem. 8235

23. Aslam H M, Burden A G, Chapman N B, Shorter J and Charton M 1981 J. Chem. Soc. Perkin Trans. 2. 500
24. Mohajer D and Tangetaninejad S 1994 Tetrahedron Lett. 35845

25. Modena G and Maioli L 1957 Gazz. Chim. Ital. 87 1306

26. Wiberg K B 1965 Oxidation in organic chemistry, Part A (New York: Academic Press)

27. Chang Y W and Westheimer F H. $1960 \mathrm{~J}$. Am. Chem. Soc. 82 1401; Rocek J and Westheimer F H $1962 \mathrm{~J}$. Am. Chem. Soc. 842241

28. Loonker K, Sharma P K and Banerji K K 1997 J. Chem. Res.(S) 194; (M), 1262

29. Vyas S and Sharma P K 2002 Proc. Indian Acad. Sci. (Chem. Sci.) 114137

30. Panigrahi G P and Mahapatro D D 1981 Int. J. Chem. Kinet. 1385

31. Meenakshisundram S and Amutha M 1999 J. Chem. Res.(S) 02; (M) 219 